\title{
O GESTO MAQUIINICO NA ANÁLISE E NA VISUALIZAÇÃO DE GRANDES COLEÇÕES DE IMAGENS
}

\section{THE MACHINIC GESTURE IN THE ANALYSIS AND VISUALIZATION OF BIG VISUAL DATA}

\author{
DONDERO, Maria Giulia Dondero' \\ Pesquisadora do Fonds National de la Recherche Scientifique \\ Professora da Université de Liège, Bégica. \\ Orcid Id: https://orcid.org/0000-0003-2320-8130
}

Tradução

\section{SCHWARTZMANN, Matheus Nogueira}

Professor do Departamento de Linguística da Faculdade de Ciências e Letras da Unesp, câmpus de Assis, e do Programa de Pós-graduação em Linguística e Língua Portuguesa da Unesp, câmpus de Araraquara.

E-mail: matheus.schwartzmann@unesp.br.

Orcid Id: https://orcid.org/0000-0002-2887-3570

\section{CASTRO, Gustavo Henrique Rodrigues}

Doutorando do Programa de Pós-graduação em Linguística e Língua Portuguesa da Unesp,

câmpus de Araraquara.

E-mail: g.castro@unesp.br.

Orcid Id: https://orcid.org/0000-0003-4486-9579

\section{RESUMO:}

Neste artigo, analisamos o trabalho de computação na base das análises quantitativas de grandes coleções de imagens (Big Visual Data) - tais como aquela praticada por Lev Manovich e o "Cultural Analytics Lab" na Media Visualization - e sua relação com nossa gestualidade sensório-motora. Nosso objetivo é o de compreender qual tipo de "simulacro de gestualidade" é instaurado na Média Visualization e, mais precisamente, o de estudar a maneira por meio da qual essas visualizações produzidas por um trabalho de computação engendram uma nova espécie de "simulacro gestual" que é assim oferecido ao observador/manipulador final de imagens. Para esse fim, convocaremos a teoria da enunciação, especialmente aquela formulada pela semiótica greimasiana e pós-greimasiana, que nos permitirá estudar a relação entre a interpretação humana e o trabalho maquínico.

1 Agradeço a Pierluigi Basso Fossali, Marion Colas-Blaise e Rémi Bernard pelas releituras deste texto e por seus preciosos conselhos. 
Palavras-chave: Computação. Máquina. Visualização. Media Visualization.

Enunciação. Gesto.

\section{ABSTRACT:}

In this article we analyze the relation between the computational work that underlies quantitative analyses of vast collections of images (Big Visual Data), as performed by Lev Manovich and the Cultural Analytics Lab in the field of Media Visualization, and our sensorymotor gesturality. Our objective is to understand what kind of "gestural simulacrum" is established in Media Visualization and to examine how these visualizations created by computational means generate a new kind of "gestural simulacrum" which is then made available to the observer/ person manipulating the final images. To this end we will call upon the theory of enunciation formulated by Greimassian and Post-Greimassian semiotics, which provides a framework to study the relation between human interpretation and machine work.

Keywords: Computation. Visualization. Media visualization. Enunciation. Gesture.

\section{INTRODUÇÃO}

Neste artigo ${ }^{2}$, pretendemos lançar nossa atenção sobre o trabalho de computação na base de análises quantitativas de grandes coleções de imagens (Big Visual Data), tais como aquela praticada por Lev Manovich e o "Cultural Analytics Lab"3 na Media Visualization. Nosso objetivo é o de compreender qual tipo de "simulacro de gestualidade" 4 é instaurado nas representações visuais da Media Visualization ${ }^{5}$, entendendo essas últimas como verdadeiras análises de córpus. Trata-se de ver se e de que maneira essas visualizações produzidas por um trabalho de computação engendram uma nova espécie de "simulacro gestual", que seria assim oferecido ao observador/manipulador final das imagens. Para tanto, convocaremos a teoria da enunciação, especialmente aquela formulada

2 Artigo original: Cf. Dondero (2019d).

3 Disponível em: http://manovich.net. Acesso: out. 2019.

4 O termo "simulacro" de gesto é utilizado não somente por razões da teoria semiótica — que nós explicitaremos mais adiante - mas também por razões mais específicas ao fazer humano. O que interpretamos, na visualização, como um "gesto" de distribuição de imagens sobre uma superfície, é identificável, do ponto de vista da máquina, somente como um conjunto de comandos visando operações que serão realizadas por algoritmos. Essa distribuição de imagens não é efetivamente realizada por uma instância sensório-motora, mas sim pela execução de um comando gerido por um software. Entretanto, essa execução é interpretada por nós segundo o funcionamento de nossa sensório-motricidade, a saber como um gesto "analogisante" que remete a nosso corpo. Sobre os simulacros de sensório-motricidade, ver Fontanille (2011) e Dondero (2019c).

5 Nós chamaremos "visualizações" as representações visuais resultantes de um trabalho de análise computacional realizado sobre imagens (quadro, fotos, etc.) constituindo uma coleção. 
pela semiótica greimasiana e pós-greimasiana, que nos permitirá estudar a relação entre a interpretação humana e o trabalho maquínico.

Tendo em vista que os estilos enunciativos das linguagens de programação já foram explorados em um importante artigo de Valle e Mazzei (2017), que explica a maneira por meio da qual a pessoa, o espaço e o tempo são declinados nas linguagem de programação imperativa, funcional e orientada por objeto (POO), desejamos compreender aqui se e de que maneira as visualizações produzidas com o software $R$ por Manovich e seus colaboradores permitem fazer emergir uma nova maneira de visualizar imagens "expostas" juntas sobre uma superfície única. Já de início, deve-se destacar que o fato de apresentar coleções de milhares de imagens sobre uma superfície única, distribuídas segundo lógicas particulares, é certamente concebível como um desafio que a máquina lança à nossa percepção.

Este trabalho consiste em identificar "gestos enunciativos inscritos" nessas visualizações de imagens (nível da "enunciação enunciada"), bem como os próprios gestos enunciativos que o observador é convidado a realizar diante dessas visualizações (nível do "ato enunciativo"). Por gesto enunciativo, entendemos, do ponto de vista da produção, as manipulações realizadas pela computação visando à produção de visualizações/análises de imagens e, do ponto de vista da recepção, os movimentos oculares e cognitivos do observador/ visualizador de imagens, que as apreende de maneira nova em relação ao modo do "close Reading". Como estamos habituados a essa leitura aproximada, que produz uma relação privilegiada com cada imagem isoladamente, o observador, diante da visualização de grandes coleções de imagens, apreende-as todas de uma só vez ("distant reading" ${ }^{6}{ }^{6}$, pois elas estão dispostas, até mesmo distribuídas, sobre uma única superfície de inscrição? .

Por "enunciação enunciada", entendemos "o simulacro que imita, no interior do discurso, o fazer enunciativo: o 'eu', o 'aqui' ou o 'agora' encontrados no discurso enunciado, não representam de maneira nenhuma o sujeito, o espaço e o tempo da enunciação" (GREIMAS; COURTÉS, 2016, p. 168). Do ponto de vista da enunciação enunciada, estudaremos as marcas da produção maquínica deixadas na visualização, ao passo que do ponto de vista do ato enunciativo,

6 Sobre o close reading e o distant reading, ver Moretti (2005).

7 Sobre o valor acrescido pela visualização totalizante da coleção sobre um único suporte, isto é, compreendendo o conjunto de elementos que constituem essa coleção - sem passar por reduções da coleção em símbolos abstratos — ver Manovich (2015) e Dondero (2017; 2018). 
lançaremos nossa atenção sobre os novos gestos, tanto oculares quanto cognitivos, que o observador/analista/manipulador de visualizações é convidado a realizar.

A produção e a recepção estão implicadas nos dois níveis da teoria da enunciação. Isso porque, no quadro da enunciação enunciada, a produção é analisável — durante o ato de observação — a partir dos traços que ela deposita no âmbito da visualização, ao passo que, no quadro do ato enunciativo, o observador é uma resposta aos traços da produção, assim como uma ação de exploração perceptiva e de manipulação no que diz respeito à visualização.

\section{TRABALHO DA COMPUTAÇÃO NA MEDIA VISUALIZATION}

A Media Visualization produz visualizações englobando grandes coleções de imagens (pintura, fotografia, desenhos gráficos), de sequências de filmes (Um homem com uma câmera, de Vertov, por exemplo), ou de ações cotidianas realizadas em lugares-chave das metrópoles, como no projeto On Broadway ${ }^{8}$. Essas visualizações de grandes coleções de imagens têm vários objetivos: compreender as mudanças do estilo pictural no curso dos séculos, a transformação das tendências fotográficas passadas e contemporâneas identificáveis no Instagram, os hábitos perceptivos e representacionais dos habitantes ou dos turistas nas metrópoles contemporâneas, etc. ${ }^{9}$

Embora essas análises quantitativas de grandes córpus sejam muito criticadas por uma parte dos pesquisadores em Humanidades, elas se revelam muito úteis e muito utilizadas por aqueles que identificam, nesses tipos de análises computacionais, recursos para a exploração de dados massivos que não podem ser gerados apenas pelo sincretismo da mão e do olho do observador ${ }^{10}$. O termo exploração permite descrever muito bem a utilidade desses mapas de coleções de imagens, que seria a de dispor de uma visão de conjunto da totalidade da coleção, na qual os elementos podem ser distribuídos de duas maneiras diferentes: segundo sua cronologia produtiva (ou por meio de outras espécies de metadados), ou ainda segundo estratégias de análise de parâmetros visuais ("extração" de qualidades plásticas). O objetivo é o de discernir, nessa totalidade de regiões de imagens que nos informam sobre similitudes e diferenças no âmbito da coleção, uma série de aspectos analíticos que,

8 Disponível em: http://www.on-broadway.nyc. Acesso em: nov. 2019.

9 A esse respeito, ver Indaco e Manovich (2016).

10 Para uma reflexão sobre a relação entre análise quantitativa, especialmente semiótica, e análise quantitativa de imagens, ver Dondero (2019a). 
em contrapartida, não poderíamos identificar diante de uma coleção de imagens necessariamente limitada e dispersa sobre vários suportes, por causa da mobilização de um único meio de investigação: nossa percepção e nossa memória.

A exploração é, portanto, antes de tudo, uma atividade produzida pelo trabalho computacional que se articula, no caso analisado, em duas direções: 1. reunir a coleção inteira; 2. reagrupar as imagens da coleção segundo parâmetros cronológicos e/ou plásticos que permitam um trabalho analítico - entendendo por análise operações de divisão, distribuição, decomposição/recomposição.

É evidente que os gestos de reunir uma totalidade de dados (compilar) e, em seguida, de posicionar essa totalidade (reagrupar) sobre a superfície única da visualização são ações conduzidas e desenvolvidas pela máquina, que pode explorar aprendizagens supervisionadas ou não supervisionadas para esse propósito. Retornaremos a isso mais adiante.

Antes de avançarmos, é preciso ressaltar que já empreendemos diversas pesquisas tendo como objeto a Media Visualization: a primeira é consagrada à questão do quadro no quadro (imagens meta) e coloca em contraste a tradição pictural e as visualizações de imagens produzidas por meios computacionais (DONDERO, 2016b); a segunda concerne às estratégias de sequencialização e de agrupamento das imagens no âmbito das visualizações (montagem e diagrama de imagens) (DONDERO, 2017); a terceira coloca o problema da manejabilidade das imagens digitais (variabilidade, modularidade, etc.) (DONDERO, 2018); a quarta incide sobre a comparação entre análise qualitativa e análise quantitativa (DONDERO, 2019a); e, por fim, a quinta concerne à remediatização dos suportes das imagens (pintura, foto) nas visualizações digitais (DONDERO, 2019b).

Este trabalho não retomará essas questões, pois tem por objetivo compreender essa abordagem de visualização de imagem segundo duas perspectivas inéditas. A primeira concerne à maneira por meio da qual a análise quantitativa de dados massivos produz uma nova forma de expor as imagens e de as colocar à disposição da visualização do observador, que depende de uma "enunciação maquínica"11. Entretanto, o hábito e a necessidade que temos de reconhecer no mundo, mesmo

11 A noção de "enunciação maquínica" foi proposta e analisada por Basso Fossali (2008) nas diferentes manifestações (automação, autorregulação, autorreferencialidade, erro). Em todos os casos examinados (da prótese à inteligência artificial), o autor a coloca constantemente em relação com o ecossistema de valores antrópicos bem como com ações/reações da percepção humana. 
aquele produzido pela máquina, alguma analogia com nossa sensóriomotricidade, decorre do fato de que somos naturalmente levados a atribuir uma espécie de "gestualidade de composição" à visualização. Como é possível descrever essa espécie de gestualidade de composição maquínica que é reinterpretada por nossa percepção analogisante? Detemo-nos a esse ponto. Podemos falar em gestos da máquina? Não, se entendermos os gestos como qualquer coisa de efêmera, de instável, que faz parte do continuum da sensório-motricidade especificamente humana $^{12}$. No entanto, não se pode esquecer que atribuímos um "envelope corporal" (ANZIEU, 1985; FONTANILLE, 2011) a todo objeto, inclusive às visualizações resultantes do trabalho de máquinas, como aquelas que examinamos aqui. Todos os gestos (reunir, compor, etc.) engendrados por comandos fornecidos por uma escritura informática e realizados por um software, na realidade, são relidos por meio de uma espécie de relação inter-actancial pelo utilizador/observador ${ }^{13}$.

A segunda problemática concerne aos modelos de gesto que nos são oferecidos/permitidos por essas visualizações: como eles reconfiguram nossa maneira de olhar e de nos posicionar diante das imagens ${ }^{14}$ ? O que resta de nossa maneira de olhar ("close reading"), tal como a praticamos diante dos livros de reprodução de imagens ou nos museus, nessa perspectiva que busca olhar tudo ao mesmo tempo ("distant reading"), em uma visualização que podemos manipular parcialmente? ${ }^{15}$.

\section{UMA NOVA VISIBILIDADE MAQUÍNICA}

Retornemos à primeira questão: o desafio que os novos tipos de análise de imagens produzidas pelas visualizações computacionais laçam aos nossos hábitos perceptivos.

12 Para uma definição do gesto humano com relação às instâncias enunciativas, ver Basso Fossali (2017). Nesse artigo, o autor posiciona o gesto como um intermediador compartilhado entre o sistema linguajeiro ("o império dos signos") e a ação finalizada no meio.

13 Sobre a perspectiva dos envelopes corporais em robótica, ver Kaplan e Oudeyer (2008).

14 Krajewski (2011) parte de uma homogeneização dos gestos do ponto de vista do utilizador: clicar sobre um ícone equivaleria a executar um conjunto muito vasto de gestos que não têm mais nenhuma analogia com os gestos físicos evocados. Portanto, toda forma de esquematização gestual não estaria mais "conforme a norma", tendo o gesto do "clique" perdido todo traço de motivação.

15 Entretanto, nos seus trabalhos, Manovich afirma que se pode entender a interatividade como uma espécie de comunicação na qual, longe de receber uma mensagem bem fechada, torna possível manipular diretamente os dados, isto é, reorganizá-los, descobrir suas relações por nós mesmos (MANOVICH, 2002). Mais radical no que diz respeito à questão da interatividade, o artigo de Chun (2005) afirma que a maior parte dos programadores são utilizadores: "Importantly, programmers are users: they create programs using editors, which are themselves software programs. The distinction between programmers and users is gradually eroding, not only because users are becoming programmers (in a real sense programmers no longer program a computer; they code), but also because, with high-level languages, prorammers are becoming more like simple users. The difference between users and programmers is an effect of software" (CHUN, 2005, p. 38). 
Em nossos trabalhos precedentes (DONDERO, 2017; 2018), identificamos dois tipos de visualização de imagens: chamamos o primeiro de "montagem de imagens" e o segundo de "diagrama de imagens". O primeiro se caracteriza pelo fato de que as imagens da coleção são programadas umas após as outras, em uma sequência que respeita metadados padrão (por exemplo, a data), ou seja, regras externas à imagem. A sintaxe de leitura dessa visualização é aquela dos textos escritos ocidentais, a serem lidos da esquerda para direita e de cima para baixo. Esse tipo de organização permite perceber o ritmo das transformações em diacronia e detectar as tendências que se desenvolvem de maneira gradual no tempo.

Nos outros tipos de visualização, outra estratégia de composição é usada, e decorre de um padrão "diagramático". Nesse caso, antes da totalização da coleção de imagens em uma única visualização, Manovich e sua equipe utilizam procedimentos de extração de qualidades visuais de imagens que eles desejam analisar e em seguida, uma vez calculadas as intensidades e as medidas das qualidades visuais da coleção, os pesquisadores procedem ao "posicionamento sobre uma grade" de valores identificados. É assim que as imagens que se parecem mais serão agrupadas em uma mesma porção de espaço, longe dos grupos de imagens diferentes.

Assim, percebemos que estamos diante de visualizações em que imagens são sobrepostas a outras, pois elas "preenchem" as mesmas zonas na grade de valores (intensidade de luminosidade, ângulos das formas, saturação cromática etc.). De certa maneira, a disposição de imagens sobre a superfície da visualização é "guiada" pela disposição prévia de grades de valores digitais.

Chamamos esse tipo de visualização de "diagramas de imagens", porque a disposição das imagens decorre de uma trama de relações de distância proporcional às diferenças e às similitudes entre as imagens. Desse modo, essas visualizações implicam um jogo de relações apreendido em uma forma global - o que caracteriza o diagrama ${ }^{16}$.

Os tipos de visualização estão postos em contraste nessa captura de tela extraída do vídeo de Jeremy Douglass, que tem por título "Mark Rothko Paintings - on the 287-Megapixel HIPerSpace Wall at Calit2":

16 Podemos definir um diagrama como uma totalidade experimental em que manipulações de relações são possíveis. Ver, sobre esse assunto, Chauviré (2008), Dondero e Fontanille (2012). 
Figura 1 - Cultural Analytics (Jeremy Douglass), 2009, Mark Rothko Paintings - on the 287-Megapixel HIPerSpace Wall at Calit2, 0:41. "All work by Lev Manovich and his team is available under Creative Commons AttributionNonCommercial-ShareAlikelicense (CC BY-NC-SA).

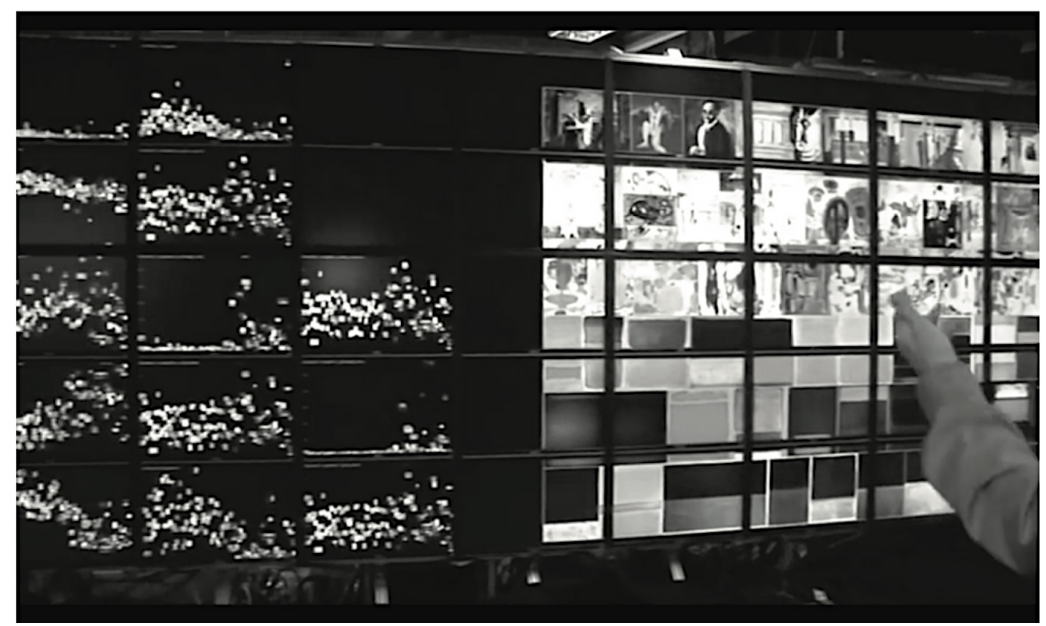

Fonte: Cultural Analytics Lab (http://lab.culturalanalytics.info). Disponível em: https://www.youtube.co m/ watch? $=-$ YIT1q FhJhk /.

À esquerda, temos a coleção disposta em "diagrama de imagens" ao passo que a parte direita mostra os mesmos quadros de Rothko dispostos segundo uma ordem cronológica (montagem). Identificamos nessas duas estratégias de composição da totalidade um gesto que é anterior à distinção entre montagem e diagrama: aquele de reunir todos os elementos que compõem uma coleção sobre um suporte que já é demarcado por grades digitais.

Tentemos dar um passo atrás antes de retornar ao vídeo de Jeremy Douglass. Qual é a operação anterior que permite tornar legíveis essas montagens e esses diagramas? Quais instâncias enunciam essas visualizações? Elas são múltiplas. Podemos listar quatro, que constituem uma estratificação de camadas enunciativas:

1. A primeira camada pode ser concebida como o ato de indexação de uma base de dados que permite selecionar a coleção a se analisar ${ }^{17}$;

2. A segunda camada enunciativa é caracterizada pelos objetivos da análise e a escolha de parâmetros pertinentes ao estudo - o que, no caso dos diagramas de imagees, coincide com a extração de uma seleção de qualidades plásticas que fazem parte da coleção;

17 A respeito das bases de dados relacionais, ver o excelente artigo de Boullier e Crépel (2013), que descreve a maneira por meio da qual podemos decompor uma imagem (no caso, uma foto reproduzida em $A$ câmara clara de Roland Barthes) em etiquetas (tags) que permitirão relacioná-la com coleções de imagens variadas. Sobre a decomposição segundo características plásticas, e não mais segundo metadados, ver Dondero (2019b). 
3. A terceira camada concerne às maneiras de instruir a máquina para o trabalho de análise das imagens arquivadas. De fato, a enunciação dessas visualizações pode depender de duas maneiras de elaborar o córpus: por aprendizagem supervisionada ou por aprendizagem nãosupervisionada. A aprendizagem supervisionada segue os parâmetros determinados pelos exemplos escolhidos pelo analista, ao passo que o método não-supervisionado deixa a iniciativa do agrupamento para a máquina ${ }^{18}$;

4. O quarto estrato enunciativo concerne ao design da interface que organiza a coleção estudada. Essa camada é a mais "superficial" no sentido de que ela é uma interface com nossa percepção. Trata-se de uma coerção topológica que prepara e guia a disposição dos grupos de imagens sobre a superfície de visualização e que podemos aproximar de uma espécie de esquematização, que chamamos em semiótica de "suporte formal" (FONTANILLE, 2005; DONDERO; REYES, 2016a). Essa esquematização está organizada na Media Visualization em abscissas e coordenadas que detêm o papel de "coerção" na distribuição dos dados visuais nas diferentes regiões de imagens. Como Pierluigi Basso Fossali nos apontou (comunicação privada), essa camada funciona também como uma enunciação editorial que permite tornar visível o trabalho realizado pelas camadas por meio das quais é constituída a análise.

Portanto, é a partir dessa interface que podemos perceber o trabalho da máquina sob a forma de gestos, isto é, como simulacro de gestos. Podemos descrever esses últimos a partir do vídeo já mencionado, que é uma excelente ilustração das manipulações que podemos operar sobre uma coleção de imagens particular, especialmente os quadros produzidos par Mark Rothko durante toda sua carreira. Como o diz Jeremy Douglass em seu vídeo, essas imagens estão posicionadas sobre a superfície da tela segundo sua textura, brilho, tipo de formas, saturação etc.

As capturas de tela a seguir permitem fixar certos gestos do explorador da coleção (que vimos dispostos em montagem e em diagrama na figura 1), visualizados aqui (figura 2 e 3) como vários diagramas de imagens, cada um disposto sobre um espaço que constitui o "287-Megapixel HIPerSpace Wall" do centro de pesquisa "Calit2" da Universidade da Califórnia em San Diego (UCSD):

18 Ver, por exemplo, o artigo na enciclopédia livre Wikipédia. Disponível em: https://fr.wikipe-dia.org/wiki/ Apprent issage_non_supervisé. Aceso em: out. 2018. 
Figura 2 - Cultural Analytics (Jeremy Douglass), 2009, Mark Rothko Paintings - on the 287-Megapixel HIPerSpace Wall at Calit2, 0:52. "All work by Lev Manovich and his team is available under Creative Commons AttributionNonCommercial-ShareAlikelicense".

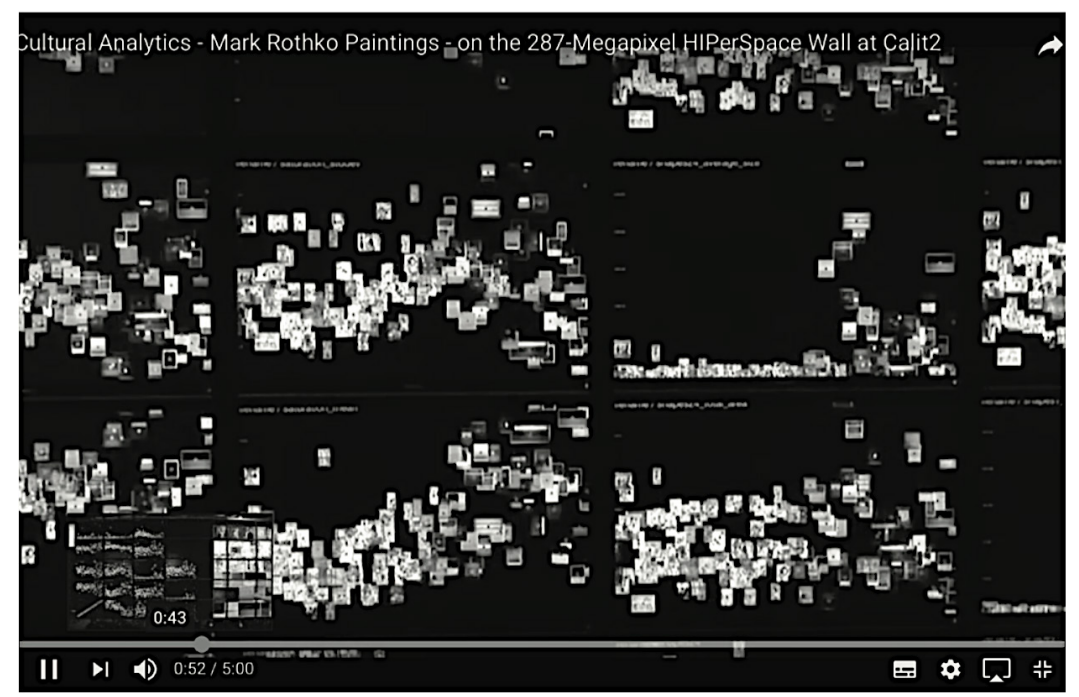

Fonte: Cultural Analytics Lab (http://lab.culturalanalytics.info). Disponível em: https://www.youtube.co m/ watch?v=-YITlq FhJhk /.

Figura 3 - Cultural Analytics (Jeremy Douglass), 2009, Mark Rothko Paintings - on the 287-Megapixel HIPerSpace Wall at Calit2, 0:51. All work by Lev Manovich and his team is available under Creative Commons AttributionNonCommercial-ShareAlikelicense (CC BY-NC-SA).

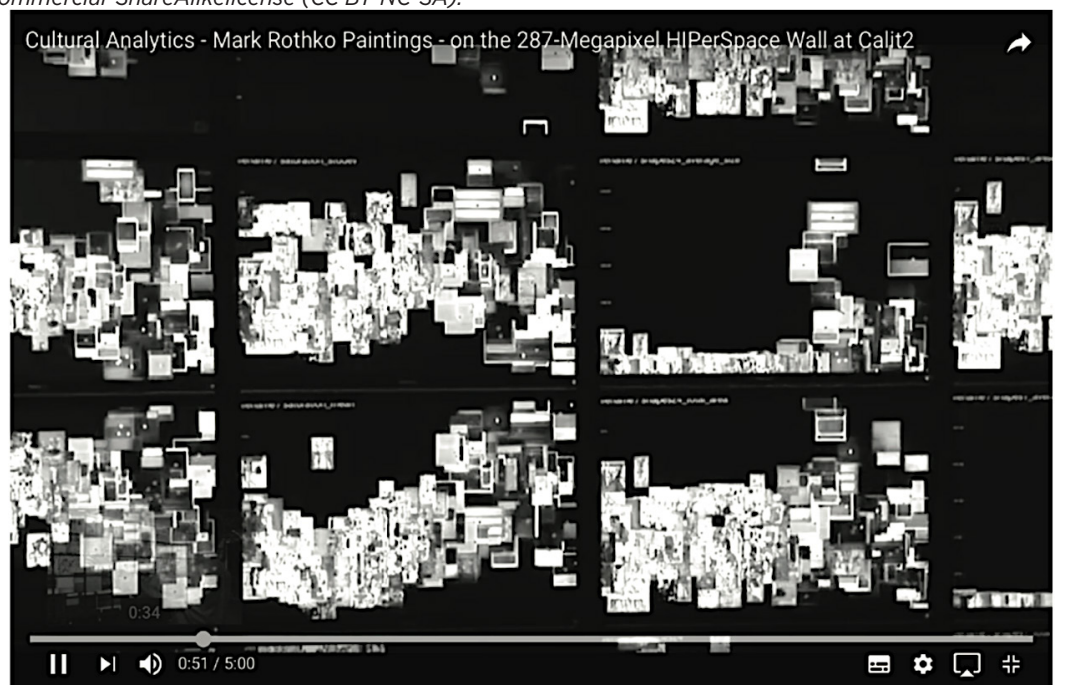

Fonte: Cultural Analytics Lab (http://lab.culturalanalytics.info). Disponível em: https://www.youtube.co m/watch?v=YIT1q FhJhk. 
Entre as figuras 2 e 3, podemos perceber uma mudança de tamanho nas imagens da coleção. Os quadros mudam de dimensão todos ao mesmo tempo a partir de um comando do observador/analista que gerencia a totalidade de imagens. Um único comando transforma o tamanho de todas as imagens a um só "clique". Não percebemos essas transformações como graduais; parece, na verdade, que as transformações se realizam por "saltos" discretos. O que é surpreendente para a percepção humana é que, com um único gesto, associado a um gesto contrário, podemos mudar o tamanho das imagens e retornar, por último, àquela de origem, em menos de um segundo.

Trata-se de uma metamorfose em que as relações não mudam, mas apenas certos parâmetros tais como o tamanho: esse último se transforma, porém, as relações no âmbito da rede permanecem intactas. Nas capturas de tela a seguir (figuras 4 e 5), as imagens estão presentes enquanto tais, quase como obras de arte, e enquanto "pontos" que podemos definir como uma espécie de medida resultante de um ato de cálculo de intensidade média de cada qualidade plástica analisada.

Figura 4 - Cultural Analytics (Jeremy Douglass), 2009, Mark Rothko Paintings - on the 287-Megapixel HIPerSpace Wall at Calit2, 0:55. All work by Lev Manovich and his team is available under Creative Commons AttributionNonCommercial-ShareAlikelicense (CC BY-NC-SA).

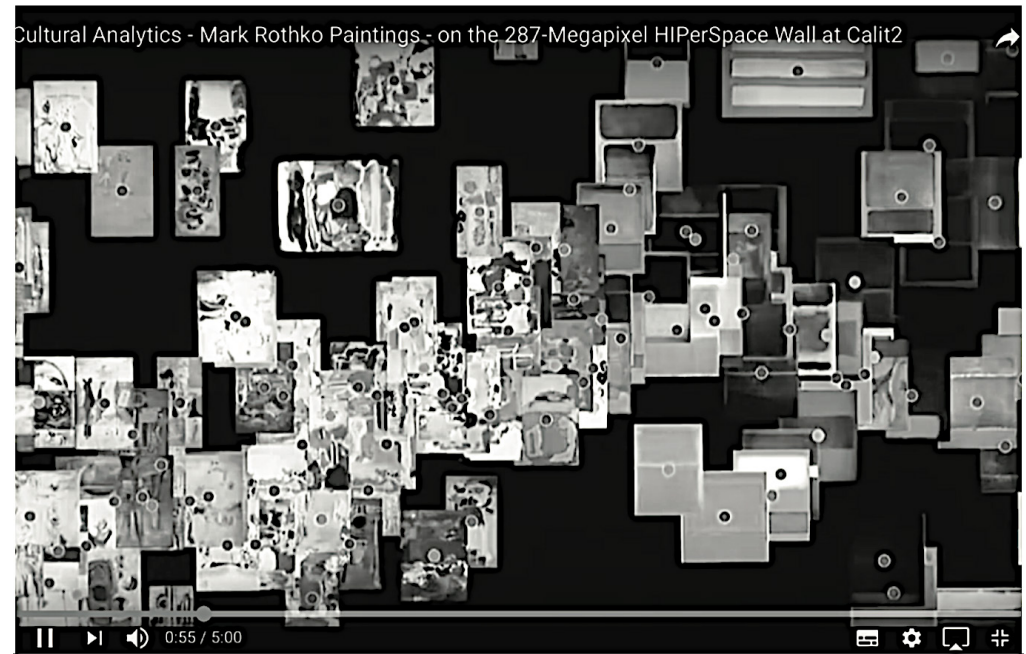

Fonte: Cultural Analytics Lab (http://lab.culturalanalytics.info). Disponível em: https://www.youtube.co m/ watch?v=-YIT1q FhJhk.

Como mostra a figura 5, a visualização também pode ser feita sem colocar em cena a totalidade da coleção de obras de arte, deixando aparecer somente as medidas sob a forma de pontos que ordenam a coleção. 
Figura 5 - Cultural Analytics (Jeremy Douglass), 2009, Mark Rothko Paintings - on the 287-Megapixel HIPerSpace Wall at Calit2, 1:27. II work by Lev Manovich and his team is available under Creative Commons AttributionNonCommercial-ShareAlikelicense (CC BY-NC-SA).

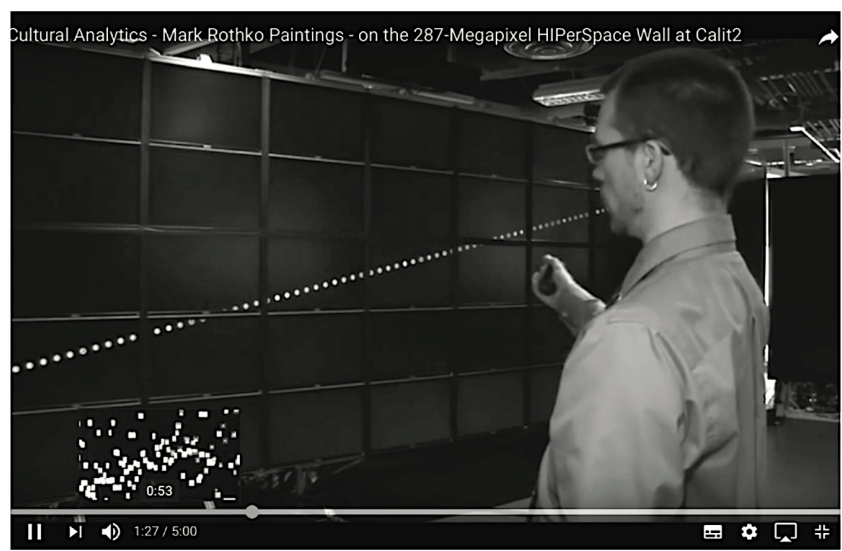

Fonte: Cultural Analytics Lab (http://lab.culturalanalytics.info). Disponível em: https://www.youtube.com/ watch?v=-YIT1q FhJhk.

Outras operações são possíveis. Como mostra a imagem seguinte (Figura 6), podemos destacar uma imagem que emerge da coleção e fixá-la no primeiro plano graças ao fato de que as outras se tornam transparentes. As imagens da coleção, dispostas segundo os parâmetros, restam assim semivisíveis no último plano como uma trama que permite a orientação na coleção e a identificação da posição da imagem emergente no seio da totalidade.

Figura 6 - Cultural Analytics (Jeremy Douglass), 2009, Mark Rothko Paintings - on the 287-Megapixel HIPerSpace Wall at Calit2, 1:46. All work by Lev Manovich and his team is available under Creative Commons AttributionNonCommercial-ShareAlikelicense (CC BY-NC-SA).

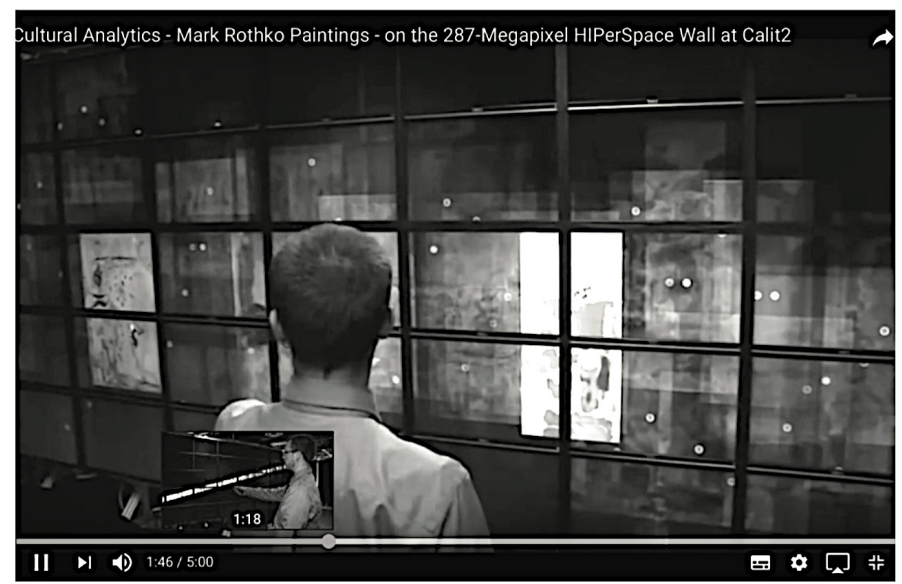

Fonte: Cultural Analytics Lab (http://lab.culturalanalytics.info). Disponível em: https://www.youtube.co m/ watch?v=-YIT1q FhJhk. 
A imagem seguinte (figura 7) mostra outro tipo de seleção de imagens. Não se trata mais de "escolher" uma imagem e de fazêla emergir em primeiro plano, deixando a totalidade da coleção em último, mais de "identificar" casos singulares no seio da distribuição das imagens. Noutras palavras, uma imagem distante de todas as outras que com frequência se sobrepõe, pois elas compartilham dos mesmos valores de intensidade, por exemplo brilho, saturação, etc. - "pede" para ser estudada. Como afirma J. Douglass, essa imagem distante das outras rompe com o padrão da coleção ("this breaks the pattern").

Trata-se de uma imagem incomum, única na carreira de Rothko - que não retornará mais sobre esse tipo de esquema de composições nem sobre essas escolhas cromáticas no resto de sua obra. A visualização permite, portanto, identificar um hápax na obra de Rothko.

Figura 7 - Cultural Analytics (Jeremy Douglass), 2009, Mark Rothko Paintings - on the 287-Megapixel HIPerSpace Wall at Calit2, 2:16. All work by Lev Manovich and his team is available under Creative Commons AttributionNonCommercial-ShareAlikelicense (CC BY-NC-SA).

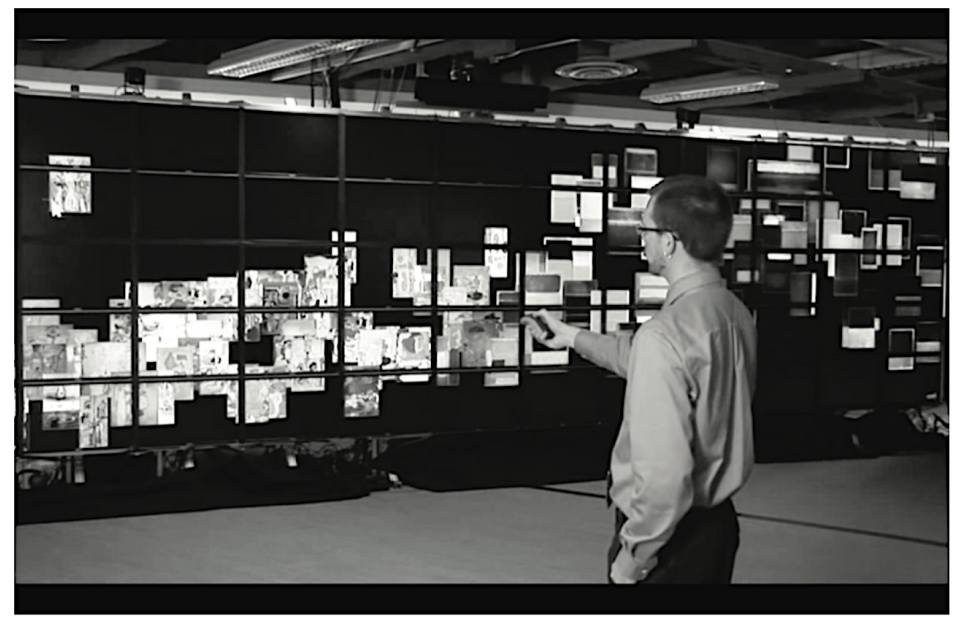

Fonte: Cultural Analytics Lab (http://lab.culturalanalytics.info). Disponível em: https://www.youtube.co m/ watch?v=-YIT1q FhJhk.

Evidentemente, podemos retirar essa imagem "incomum" de sua posição periférica e colocá-la em primeiro plano para compará-la com outras e identificar aquilo que a distingue e faz dela uma exceção. Retirando-a de sua posição periférica por um gesto de "ateriorização", fazemos com que ela perca sua posição e, por consequência, suas coordenadas relacionais. Nas operações concernindo à figura 6, ao contrário, a imagem emergente da trama transparente da coleção 
mantinha sua posição, tendo em vista que as outras imagens lhe "davam espaço" se retirando de vista para uma zona de semi-invisibilidade.

Dessa rápida descrição emerge o fato de que, diante dessas visualizações, os gestos enunciativos emergem da interface e se endereçam ao observador. O primeiro desses gestos é, como já dissemos, aquele de compilar e de reunir a coleção sobre uma única e exclusiva superfície, o que coincide com uma operação de monitoramento e de domínio da coleção ${ }^{19}$. Outros simulacros de gestos são ofertados ao observador: a transformação do tamanho da coleção inteira - o que permite destacar melhor a estrutura medindo as qualidades plásticas das imagens - , a extração de uma imagem de sua região, a construção de uma separação entre primeiro-plano e último-plano da coleção, etc.

\section{A VISUALIZAÇÃO DE IMAGENS ENTRE PARADIGMA E SINTAGMA}

Ainda que, sobre o plano do conteúdo, essas visualizações possam mostrar transformações estilísticas diacrônicas por meio dos padrões que elas desenham, elas dispõem as imagens sobre o suporte de interface de forma que constroem uma totalidade dificilmente legível como narrativa $^{20}$. Essas visualizações nos propõem, na verdade, a mise en scène de um paradigma de opções, um sistema de virtualidades que pode ser mais ou menos preenchido por imagens da coleção estudada. A superposição de imagens em um mesmo lugar da superfície corrobora esta hipótese: um mesmo papel (em termos de valores plásticos) pode ser preenchido por várias imagens, ao passo que os outros papéis restam vazios, não atualizados. É por todas essas razões que não podemos ler essa visualização como uma narrativa. Essa visualização não está "ancorada no discurso", pois ela deixa abertos os caminhos a se percorrer: vários caminhos interpretativos são possíveis, deixados em suspenso, e se encontram por consequência em concorrência entre si.

Essa hipótese se aproxima da concepção que tem Lev Manovich da base de dados como uma "forma simbólica da cultura contemporânea". É preciso entender "forma simbólica" à maneira de Panofsky, que

19 Sobre o mito do monitoramento e da penetração no quadro da cultura da tela, ver Basso Fossali (2019).

20 Devemos em parte essas reflexões à intervenção feita por Jacques Fontanille no Seminário Internacional de Semiótica, em Paris ("L'invention I : Agencements critiques entre thésaurisation, imagination et programmation") na ocasião de nossa apresentação que teve por título "L'archive comme moteur d'invention" $\left(1^{\circ}\right.$. fev., 2017). Fontanille afirmou que, se seguirmos o Greimas de Semântica Estrutural (GREIMAS, 1966), o córpus escolhido determina o tipo de teoria geral do sentido. Ora, sucede que o córpus escolhido por Greimas, qual seja a literatura romanesca, produziu uma teoria do sentido sustentada pelo conceito de narratividade. Fontanille propõem considerar que, diante dessas visualizações de base de dados, a teoria do sentido que deles resulta não é mais orientada pela narratividade, mas sim por outros parâmetros, dentre os quais está aquele do paradigma. 
identificava na perspectiva linear um modelo de representação do espaço emblemático na cultura do Renascimento e da Idade Moderna. A forma simbólica da base de dados se distingue, segundo Manovich, da forma simbólica da narratividade que caracterizaria os séculos XIX e XX.

Em Le langage des Nouveaux Médias, Manovich afirma que a base de dados e a narratividade não têm o mesmo estatuto na cultura digital. Na oposição entre base de dados e narração, a base de dados acabaria por ser o termo não marcado:

Nas novas mídias, a base de dados serve de suporte a formas culturais diversas, da transposição direta (uma base de dados se apresenta como tal) a uma forma cuja lógica é oposta à de sua forma material em si, a saber a forma da narrativa. Mais precisamente, uma base de dados pode servir de suporte a uma narrativa, mas nada na lógica do mediador em si favoriza a sua geração (MANOVICH, 2001, p. 407-08).

Em todo ato de produção de uma obra, existe sempre, para o narrador, um paradigma de escolhas possíveis a partir do qual a narração é construída. É claro que nessa relação clássica entre paradigma e sintagma, na maior parte dos casos, o paradigma fica implícito ao passo que o sintagma, isto é, a discursivização, fica explícita. Manovich afirma que as novas mídias invertem essa relação, e que a base de dados entendida como paradigma de virtualidades adquire uma existência material, ao passo que a narratividade (o sintagma) restaria desmaterializado, ou seja, virtual. De fato, se retornarmos ao trabalho de Manovich constataremos que, na Media Visualisation, não se trata de desenvolver uma narração no seio da coleção, mas sim de fazer aparecer formas possíveis da coleção - distinguindo, certamente, os diferentes graus de seu potencial de realização.

\section{CONCLUSÃO}

A semiótica voltou a prestar atenção na questão do gesto somente a partir do final dos anos de 1990, e de maneira renovada com relação àquilo que dizia Greimas no final dos anos de 1960 (GREIMAS, 1968). Nesse momento, o estudo do gesto consistia em recuperar as figuras mínimas da expressão gestual que pudessem corresponder às figuras nucleares do conteúdo linguístico. Com a semiótica das práticas, a gestualidade passou a ser considerada uma delegação enunciativa cujo centro de referência é o corpo humano. No momento do deep learning, 
somos levados a compreender quais são as operações que a máquina é capaz e, especialmente, no nosso caso presente, a maneira por meio da qual essas operações podem instaurar simulacros de gestos que são totalmente novos. Esses não são apenas simulacros de gestos totalizantes (reunir grandes quantidades de dados sobre um suporte, transformar os tamanhos dessas quantidades de dados via um único comando), mas também simulacros de gestos analíticos (reagrupar, dividir, etc.) e propõem, enfim, novas formas de expor os objetos culturais via sistemas diagramáticos.

\section{REFERÊNCIAS}

ANZIEU, D. Le moi-peau. Paris: Dunod, 1985.

BASSO FOSSALI, P. L'image du devenir: le monde en chiffre et la passion du monitorage. Signata-Annales des Sémiotiques / Annals of Semiotics, v. 10, 2019. Disponível em : https://journ als.openedition.org/ signata/2261. Acesso em: nov. 2019.

BASSO FOSSALI, P. Le geste et sa niche: gestion du sens "hors technique". Texto! Textes et cultures, v. 22, n. 2, 2017.

BASSO FOSSALI, P. Vissuti di significazione. Temi per una semiotica viva. Pise: ETS, 2008.

BOULLIER, D.; CRÉPEL, M. Biographie d'une photo numérique et pouvoir des tags. Classer/circuler. Revue d'anthropologie des connaissances, v. 7, n. 4, 2013. p. 785-813.

CHAUVIRÉ, C. L'œil mathématique. Essai sur la philosophie mathématique de Peirce. Paris: Kimé, 2008.

CHUN, W. H. K. On Software, or the Persistence of Visual Knowledge. Grey Room, v. 18, n. 2651, 2005. Disponível em: https://www.brown. edu/Departments/MCM/people/chun/paper s/software.pdf. Acesso em: nov. 2019.

DONDERO, M. G. Visual semiotics and automatic analysis of images from the Cultural Analytics Lab: how can quantitative and qualitative analysis be combined? Sémiotica, n. 230, 2019a, p. 121-142. Disponível em: [DOI] https://doi.org/10.1515/sem-2018-0104. Acesso em: out. 2019. 
DONDERO, M. G. Em vias de publicaçao La remédiation de larges collections d'images via la visualisation automatique. In: COLAS-BLAISE, Marion; TORE, Gian Maria (Orgs.). La question du R. Milan: Mimésis, 2019b.

DONDERO, M. G. Le geste énonciatif et le nanoart: le sens au risque de I'infiniment petit. In: BASSO FOSSALI, P.; COLAS-BLAISE, M.; DONDERO, M. G. (Orgs.). La communication à l'épreuve du geste numérique. Revue du MEI, n. 47, 2019c, p. 27-39.

DONDERO, M. G. Le geste machinique dans I'analyse et le visionnage de larges collections d'images. Revue du MEI. Information et Mediation, 2019d, n. 47. Disponível em: http://mei-info.com/revue/47/51/. Acesso em: nov. 2019.

DONDERO, M. G. La remédiation d'archives visuelles en vue de nouvelles iconographies: le cas de la Media Visualization de Lev Manovich. Interin, v. 1, n. 23, 2018. p. 85-107. Disponível em: https:// seer.utp.br/index. php/i/issue/view/41. Acesso em: nov. 2019.

DONDERO, M. G. The Semiotics of Design in Media Visualization: Mereology and Observation Strategies. Information Design Journal, $v$. 23, n. 2, 2017. p. 208-18. Disponível em: https://www.jbe-platform. com/content/journals/10.1075/idj.23.2.09don. Acesso em: nov. 2019.

DONDERO, M. G.; REYES-GARCIA, E. Les supports des images: photographie et images numériques. Revue Française des Sciences de I'Information et de la Communication, v. 9, 2016a. Disponível em: http://rfsic. revues.org/2124. Acesso em: nov. 2019.

DONDERO, M. G. Using Images to Analyze Images. Semiotics meets Cultural Analytics. In: REYES-GARCÍA, E.; CHÂTEL-INNOCENTI, P.; ZREIK, K. (Orgs.). Proceedings of the Computer Art Congress 5: Archiving and Questioning Immateriality. Paris: Europia, 2016b, p. 91-107.

DONDERO, M. G.; FONTANILLE, J. Des images à problèmes. Le sens du visuel à l'épreuve de l'image scientifique. Limoges: Pulim, 2012.

FONTANILLE, J. Corps et sens. Paris: P.U.F., 2011.

FONTANILLE, J. Du support matériel au support formel. In: ARABYAN, M.; KLOCK- FONTANILLE, I. (Orgs.). L'Écriture entre support et surface. Paris: L'Harmattan, 2005. p. 183-200.

GREIMAS, A. J.; COURTÉS, J. Dicionário de Semiótica. 2. ed. 3. reimp. São Paulo: Contexto, 2016. 
GREIMAS, A. J. Conditions d'une sémiotique du monde naturel. Langages, v. 10, 1968, p. 3-35. Disponível em: [DOI] https://doi.org/10.3406/ Igge.1968.2546. Acesso em: nov. 2019.

GREIMAS, A. J. Semântica Estrutural. Pesquisa e Método. 2. ed. São Paulo: Cultrix, 1966.

KAPLAN, F.; OUDEYER, P-Y. Le corps comme variable expérimentale. Revue philosophique, n. 133, v. 3, 2008, p. 287-98.

KRAJEWSKI, P. La geste des gestes (extrait). Chapitre 8: où I'on découvre la nature des gestes, et comment ils ont eu à affronter les moments techniques et technologiques de l'histoire du progrès humain. Appareil, n. 8, 2011. Disponível em: http:// journals.openedition.org/ap pareil/1298. Acesso em: nov. 2019.

MANOVICH, L. Generation Flash. 2002. Disponível em: http://www. manovich.net/DOCS/gen eration_flash.doc. Acesso em: nov. 2019.

MANOVICH, L. Data Science and Digital Art History. International Journal for Digital Art History, v. 1, n. 1, 2015. p. 3-35. Disponível em: https://journals.ub.uni-heidelberg.de/index.php/dah/article/view/21631. Acesso em: nov. 2019.

MANOVICH, L. Le langage des nouveaux médias. Paris: Les presses du réel, 2010.

INDACO, A.; MANOVICH, L. Urban social media inequality: definition, measurements, and application. arXiv preprint arXiv:1607.01845, 2016. Disponível em: http://manovich.net/inde x.php/projects/social-mediainequality. Acesso em: nov. 2019.

MORETTI, F. Graphs, maps, trees: abstract models for a literary history. Londres: Verso, 2005.

VALLE, A.; MAZZEI, A. Sapir-Whorf vs. Boas-Jakobson. Enunciation and the Semiotics of Programming Languages. Lexia, n. 27-8, 2017. p. 50525 .

\section{VIDEOGRAFIA}

287-MEGAPIXEL HIPerSpace Wall; Calit2CULTURAL. Analytics - Mark Rothko Paintings - on the. Disponível em: https://www.youtube.com/ watch? $=-$ YIT1 qFhJhk. Acesso em: nov. 2019

Enviado em: 10/12/2019

Aceite em: $\quad$ 18/12/2019 